\title{
Performance Status Scale Timing Not
}

\section{Evaluated}

National Cancer Institute

\section{Source}

National Cancer Institute. Performance Status Scale Timing Not Evaluated. NCI

Thesaurus. Code C157416.

An indication that the information was not evaluated, not provided or available. 